\title{
Healthcare Costs and Resource Utilization in Patients with Infantile Spasms Treated with H.P. Acthar Gel ${ }^{\circledR}$
}

\author{
Laura S. Gold · Patricia B. Schepman · Wei-Jhih Wang • \\ Michael Philbin · John Niewoehner · Kavitha Damal • \\ Ryan N. Hansen
}

Received: April 20, 2016/Published online: June 20, 2016

(C) The Author(s) 2016. This article is published with open access at Springerlink.com

\section{ABSTRACT}

Introduction: The purpose of this study was to describe healthcare resource utilization and costs resulting from early (within 30 days of diagnosis) versus late ( $>30$ days after diagnosis) treatment with prescriptions for H.P. Acthar ${ }^{\circledR}$ Gel (repository corticotropin injection; Acthar; Mallinckrodt) to manage infantile spasms (IS).

Methods: We included all patients in the Truven Health MarketScan ${ }^{\circledR}$ Commercial

Enhanced content To view enhanced content for this article, go to http://www.medengine.com/Redeem/7AD 4F0607A27667B.

Electronic supplementary material The online version of this article (doi:10.1007/s12325-016-0361-2) contains supplementary material, which is available to authorized users.

L. S. Gold (ه) · W.-J. Wang · R. N. Hansen Department of Pharmacy, Pharmaceutical Outcomes Research and Policy Program, University of Washington, Seattle, WA, USA

e-mail: goldl@uw.edu

L. S. Gold

Department of Radiology, Pharmaceutical Outcomes Research and Policy Program, University of Washington, Seattle, WA, USA

P. B. Schepman

Regional Outcomes, Sanofi US, Bridgewater, NJ, USA
Claims and Encounters Database and the Truven Health MarketScan Multi-State Medicaid Database who were diagnosed with IS from 2007 to 2012. We performed unadjusted and adjusted regressions examining the relationship between healthcare resource utilization variables and their associated costs to compare outcomes in the early and late Acthar users.

Results: A total of 252 patients with IS who received Acthar fit our study criteria; 191 (76\%) were early Acthar users. In adjusted analyses, we found that early Acthar use was associated with, on average, 3.8 fewer outpatient services (99\% CI 0.7-6.7 fewer services). We did not find significant associations between early prescriptions for Acthar and number of hospitalizations, emergency room visits,

M. Philbin · J. Niewoehner

Health Economics and Outcomes Research, Mallinckrodt Pharmaceuticals, Hazelwood, MO, USA

K. Damal

Santen Incorporated, Emeryville, CA, USA

R. N. Hansen

Department of Health Services, Pharmaceutical Outcomes Research and Policy Program, University of Washington, Seattle, WA, USA 
prescription medications filled, or total costs of health services.

Conclusion: Patients prescribed Acthar within 30 days of their IS diagnoses tended to have fewer outpatient services performed compared to patients prescribed Acthar later in the disease process. Although additional research is needed to confirm these exploratory findings, physicians may consider early treatment with Acthar to manage IS.

Funding: This study was funded by a grant to the University of Washington from Mallinckrodt Pharmaceuticals.

Keywords: Costs; Healthcare resource utilization; H.P. Acthar ${ }^{\circledR}$ Gel (repository corticotropin injection); Infantile spasms; Neurology

\section{INTRODUCTION}

Infantile spasms (IS; West syndrome) is a rare (occurring in about 1.6-4.5/10,000 live births) [1-4], but often devastating form of epilepsy that typically occurs in the first year of life [2]. Although spasms usually resolve by age five, the long-term prognoses of infants diagnosed with IS are relatively poor, with the majority of patients developing conditions, such as refractory epilepsy, mental retardation, and autistic spectrum disorders [2, 5-9]. While the therapeutic response and complete resolution of IS largely depend on the underlying etiology and other clinical factors, early diagnosis and prompt treatment may improve neurological and developmental outcomes $[2,9,10]$.

In the US, hormonal therapies, such as intramuscular adrenocorticotropic hormone (ACTH), are commonly used to treat IS; a recent survey of clinicians treating IS reported that $84 \%$ prescribed ACTH [11]. However, only two drugs have received US Food and Drug Administration (FDA) approval to treat IS: the gamma-aminobutyric acid transaminase inhibitor vigabatrin (Sabril ${ }^{\circledR}$; Lundbeck) [12] and H.P. Acthar ${ }^{\circledR}$ Gel (repository corticotropin injection; Acthar; Mallinckrodt) [13]. Following treatment, infants typically undergo electroencephalograms (EEGs) to evaluate treatment effectiveness, which is defined as both complete cessation of spasms as well as the resolution of hypsarrhythmia on EEGs [2] and, if indicated, treatments are modified [5].

Although analysis of healthcare resource utilization in patients with convulsive disorders is the starting point for economic assessment of the medical burden of these conditions, little research has been conducted. The purpose of this study was to describe health outcomes and costs resulting from early (within 30 days of diagnosis) prescriptions of Acthar versus later (more than 30 days after diagnosis) prescriptions to generate hypotheses for future studies on healthcare utilization and treatment patterns among patients with IS.

\section{METHODS}

\section{Study Population and Data Source}

We used the Truven Health MarketScan ${ }^{\circledR}$ Commercial Claims and Encounters Database and the Truven Health MarketScan Multi-State Medicaid Database to identify the study cohort. These databases contained inpatient, outpatient, pharmacy claims, and insurance coverage data for patients across the US who are enrolled in commercial insurance plans. The inpatient and outpatient claims databases include procedure and visit-level details from medical claims, such as the International 
Classification of Diseases, Ninth Revision, Clinical Modification (ICD-9-CM) diagnosis and procedure codes, Current Procedural Terminology (CPT) medical procedure codes, dates of service, and variables describing financial expenditures. The pharmacy claims database provided details, including National Drug Codes (NDC), dates dispensed, quantity and days' supply, and payments made for each claim. A separate eligibility and demographics file provided additional information about each subject, such as age, gender, insurance plan type, geographic location, and enrollment status by month.

We included patients in the MarketScan Research Database who received treatment for IS (ICD-9-CM diagnosis code: 345.60) between April 1, 2007 and December 31, 2012 who were less than 2 years old at the time of the IS diagnosis. This age restriction is aligned with the US FDA's labeled indication for Acthar [14]. Patients with subsequent diagnoses of tuberous sclerosis complex (TSC; ICD-9-CM diagnosis code: 759.5) were excluded from our analyses. TSC is a complex genetic disorder that can affect multiple organs and is usually treated effectively with vigabatrin or surgery [15]. To have complete comorbidity and health outcome data, we also excluded patients who were not enrolled in their health plans continuously for at least 3 months prior and 12 months after the index date.

We classified patients in our study cohort who had outpatient prescriptions or procedure codes indicating the receipt of prescriptions for Acthar (NDCs: 63004-77310-1, 63004-87100-1; CPT code: J0800) into those who received Acthar prescriptions early (within 30 days of the index IS incident) and those who received Acthar prescriptions later (more than 30 days after the index IS incident). Patients who received prescriptions for Acthar within
30 days and, in addition, received prescriptions for Acthar more than 30 days after their index diagnoses were included in the early Acthar group. We assumed the subsequent prescriptions for Acthar were likely to be continuations of therapies that began within 30 days.

The MarketScan Research Database contained patient demographic variables, including age, gender, type of health insurance plan (types of private plans and Medicaid versus non-Medicaid), and geographic region (although region data were not available for patients with Medicaid). We also assessed year of IS diagnosis and the number of outpatient services, hospitalizations, and medications filled in the 90 days prior to index IS incident. In addition, we also looked for use of anticonvulsants, steroids, or vigabatrin (Sabril) prior to receipt of Acthar prescriptions (see Table S1 in the supplementary material for a complete list of these medications), previous diagnoses of major cardiac diseases, central nervous system malformations, and severe metabolic conditions (see Table S2 in the supplementary material for a complete list of the ICD-9-CM diagnosis codes included in each of these categories).

\section{Statistical Analysis}

We calculated proportions and Chi-square tests (for categorical variables) and means, standard deviations, and $t$ tests (for continuous variables) of factors that might have been related to health costs and outcomes and early receipt of Acthar prescriptions. Variables with $P$ values of $\leq 0.05$ were considered significant confounders. Next, we calculated means, medians, ranges, standard deviations, and 
differences between means of each healthcare utilization and cost among patients who received early Acthar prescriptions compared to patients who received late Acthar prescriptions. Because we made multiple comparisons $(n=15)$, we determined that $P$ values of 0.01 would represent statistically significant associations between receipt of early Acthar prescriptions and each utilization or cost outcome. We calculated adjusted means and adjusted differences between means. For outcomes with count variables, we used generalized linear regression with log links and specified the Poisson distribution to calculate adjusted means and 99\% confidence intervals (CIs). For the binary outcome of whether patients were readmitted to the hospital within 30 days of discharge, we used logistic regression to calculate odds ratios (ORs) and 99\% CIs. For cost outcomes, we used generalized linear regressions with log links and specified the gamma distribution to calculate adjusted means and 99\% CIs. To allow cost models to run, nominal amounts were added to patients with zero costs. Because the inclusion of covariates in the adjusted models affected the estimates of component costs, individual cost components did not add exactly to the adjusted total costs.

SAS for Windows, version 9.3 (SAS Institute, Inc., Cary, NC, USA) was used for all analyses.

\section{Compliance with Ethics Guidelines}

All procedures followed were in accordance with the ethical standards of the responsible committee on human experimentation (institutional and national) and with the Helsinki Declaration of 1964, revised in 2013. This study was exempt from review by the
University of Washington Institutional Review Board (IRB) through self-determination.

\section{RESULTS}

Out of 108,860,485 individuals enrolled in the MarketScan and Medicaid databases between April 1, 2007 and December 31, 2012, a total of 5158 patients with IS were identified (Fig. 1). Of these, 201 patients were excluded, because they had subsequent diagnoses of tuberous sclerosis, and 1949 patients were excluded, because they were not enrolled for at least 3 months before and 12 months after their initial IS diagnoses. We also excluded 2000 patients, because their ages were missing or they were not less than 2 years old at the time of their IS diagnoses. Of the remaining 1008 patients, 756 were excluded, because they did not receive prescriptions for Acthar. Of the 252 patients with IS who received prescriptions for Acthar, 191 (76\%) were prescribed Acthar within 30 days or less.

Demographic characteristics of patients who received prescriptions for Acthar are shown in Table 1. A smaller proportion of early Acthar prescription recipients were female compared to male (39\% versus 61\%; $P=0.03)$. A higher proportion of patients who received Acthar later filled prescriptions for anticonvulsants prior to filling prescriptions for Acthar (21\% versus $33 \% ; P=0.07)$. In addition, higher proportions of patients who received Acthar later had been diagnosed with severe central nervous system malformations prior to being diagnosed with IS (14\% versus $31 \% ; P=0.002)$. Patients who were prescribed Acthar early had fewer hospitalizations in the 90 days prior to the IS diagnosis compared to patients who were prescribed Acthar later (0.2 versus 0.6; $P=0.0002)$. Patients who were prescribed 


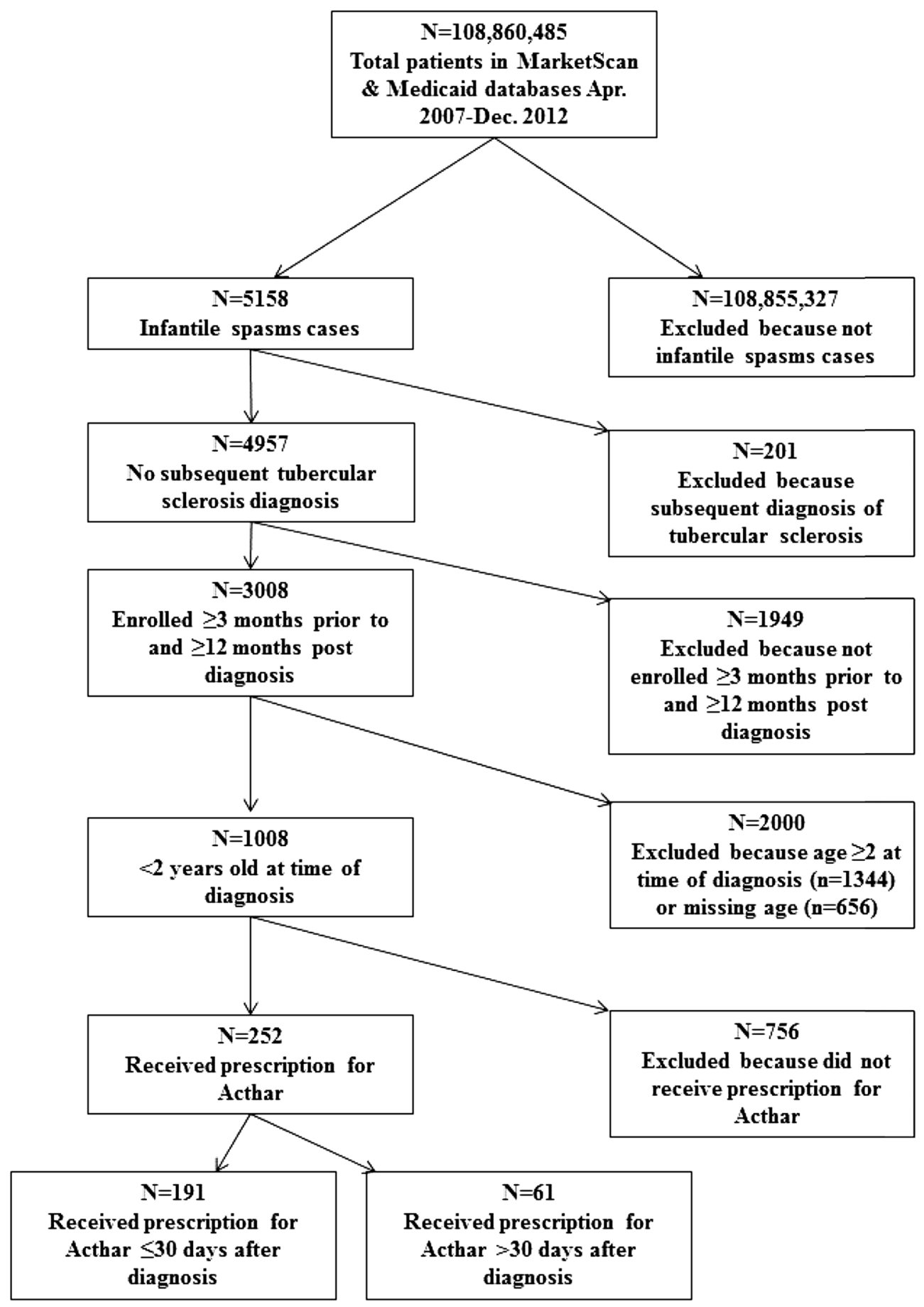

Fig. 1 Study participant flow

Acthar early were similar to those who were prescribed Acthar later in terms of age, insurance plan, geographic region, and year of IS diagnosis, whether they filled prescriptions for steroids prior to filling prescriptions for Acthar, whether they had diagnoses of major cardiac diseases or metabolic conditions, and the number of outpatient services and 
Table 1 Characteristics of infantile spasm patients prescribed Acthar within 30 days of index diagnosis compared to patients prescribed Acthar more than 30 days after diagnosis

\begin{tabular}{|c|c|c|c|}
\hline Characteristics & $\begin{array}{l}\text { Acthar } \mathrm{Rx}^{\mathrm{a}}(\leq 30 \text { days post-index }) \\
n=191(76 \%)\end{array}$ & $\begin{array}{l}\text { Acthar } \mathrm{Rx}^{\mathrm{a}}(>30 \text { days post-index }) \\
n=61(24 \%)\end{array}$ & $P$ value ${ }^{b}$ \\
\hline Age (years), mean (SD) & $0.62(0.49)$ & $0.64(0.48)$ & 0.76 \\
\hline Age 0 to $<1$ year & $73(38 \%)$ & $22(36 \%)$ & 0.76 \\
\hline Age 1 to $<2$ years & $118(62 \%)$ & $39(64 \%)$ & \\
\hline Female & $74(39 \%)$ & $33(54 \%)$ & 0.03 \\
\hline Male & $117(61 \%)$ & $28(46 \%)$ & \\
\hline Non-Medicaid & $154(81 \%)$ & $49(80 \%)$ & 0.96 \\
\hline Medicaid & $37(19 \%)$ & $12(20 \%)$ & \\
\hline \multicolumn{4}{|l|}{ Type of health plan } \\
\hline Comprehensive & $18(9 \%)$ & $9(15 \%)$ & 0.42 \\
\hline $\begin{array}{l}\text { Exclusive/preferred provider } \\
\text { organization }\end{array}$ & 93 (49\%) & $32(52 \%)$ & \\
\hline $\begin{array}{l}\text { Health maintenance } \\
\text { organization }\end{array}$ & $46(24 \%)$ & $9(15 \%)$ & \\
\hline Point of service & $19(10 \%)$ & $7(11 \%)$ & \\
\hline $\begin{array}{l}\text { Consumer-directed/ } \\
\text { high-deductible }\end{array}$ & $15(8 \%)$ & $3(5 \%)$ & \\
\hline Missing & $0(0.0 \%)$ & $1(1 \%)$ & \\
\hline \multicolumn{4}{|l|}{ Geographic region } \\
\hline Northeast & $27(14 \%)$ & $9(15 \%)$ & 0.82 \\
\hline North Central & $46(24 \%)$ & $13(21 \%)$ & \\
\hline South & $51(27 \%)$ & $16(26 \%)$ & \\
\hline West & $25(13 \%)$ & $11(18 \%)$ & \\
\hline Missing $^{c}$ & $42(22 \%)$ & $12(20 \%)$ & \\
\hline \multicolumn{4}{|l|}{ Year of IS incident } \\
\hline 2007 & $29(15 \%)$ & $7(11 \%)$ & 0.19 \\
\hline 2008 & $35(18 \%)$ & $21(34 \%)$ & \\
\hline 2009 & $34(18 \%)$ & $8(13 \%)$ & \\
\hline 2010 & $35(18 \%)$ & $11(18 \%)$ & \\
\hline 2011 & $30(16 \%)$ & $8(13 \%)$ & \\
\hline 2012 & $28(15 \%)$ & $6(10 \%)$ & \\
\hline
\end{tabular}


Table 1 continued

\begin{tabular}{|c|c|c|c|}
\hline Characteristics & $\begin{array}{l}\text { Acthar } \mathrm{Rx}^{\mathrm{a}}(\leq 30 \text { days post-index }) \\
n=191(76 \%)\end{array}$ & $\begin{array}{l}\text { Acthar } \operatorname{Rx}^{\mathrm{a}}(>30 \text { days post-index }) \\
n=61(24 \%)\end{array}$ & $P$ value $^{\mathrm{b}}$ \\
\hline \multicolumn{4}{|l|}{$\mathrm{Rx}$ filled prior to IS diagnosis ${ }^{\mathrm{d}}$} \\
\hline Steroid & $11(6 \%)$ & $6(10 \%)$ & 0.27 \\
\hline Anticonvulsant & $41(21 \%)$ & $20(33 \%)$ & 0.07 \\
\hline Vigabatrin & $0(0.0 \%)$ & $0(0.0 \%)$ & - \\
\hline \multicolumn{4}{|c|}{ Comorbidities diagnosed prior to IS diagnosis ${ }^{\mathrm{e}}$} \\
\hline Major cardiac diseases & $43(23 \%)$ & $19(31 \%)$ & 0.17 \\
\hline Metabolic conditions & $17(9 \%)$ & $6(10 \%)$ & 0.83 \\
\hline $\begin{array}{l}\text { Severe central nervous system } \\
\text { malformations }\end{array}$ & $26(14 \%)$ & $19(31 \%)$ & 0.002 \\
\hline \multicolumn{4}{|c|}{ Number of utilizations from days -90 to -1 , mean \pm SD (range) } \\
\hline Outpatient services & $10.2 \pm 9.6(0-54)$ & $12.5 \pm 9.5(1-38)$ & 0.12 \\
\hline Hospital admissions & $0.2 \pm 0.5(0-2)$ & $0.6 \pm 1.0(0-4)$ & 0.0002 \\
\hline Medications & $3.5 \pm 4.9(0-31)$ & $4.0 \pm 4.4(0-19)$ & 0.54 \\
\hline
\end{tabular}

$R x$ prescription, $S D$ standard deviation

Values are given as $n(\%)$ unless otherwise stated

a Patients could have had both early and late Acthar $\mathrm{Rx}(n=63)$

b $P$ value calculated using $t$ test for continuous variables or Chi-square test for categorical variables

c Region data missing from patients in Medicaid database

d See Table S1 for list of National Drug Codes and generic names of each type of medication

e See Table S2 for list of International Classification of Diseases, Ninth Revision, Clinical Modification diagnosis codes of each type of comorbidity

medications in the 90 days prior to diagnosis. No patients received vigabatrin prior to receiving prescriptions for Acthar.

In unadjusted analyses (Table 2), we found that patients who were prescribed Acthar within 30 days of diagnosis had non-statistically significantly reduced outpatient services (12 fewer procedures; 99\% CI -29 to 3.7), fewer inpatient, outpatient, and medication fills combined (18 fewer health services; 99\% CI -40 to 3.9 ), and similar costs. The two groups were similar in terms of number of hospitalizations, mean length of stay per hospitalization, number of admissions to the intensive care unit, readmissions within 30 days, emergency room visits, hospitalization costs, and total costs. Following adjustment for gender, comorbid diagnoses of central nervous system disorders, and hospitalizations in the 90 days prior to the IS diagnosis (Table 3), the association between early Acthar prescriptions and the number of outpatient services became statistically significant (3.8 fewer outpatient procedures; $99 \%$ CI -6.7 to -0.7$)$ as did the reduced number of total health services (4.2 fewer total health services; $99 \% \mathrm{CI}-7.9$ to -0.4 ). We also found that, among patients who had at least one hospitalization, those who received Acthar early were almost twice as likely to have been readmitted within 30 days, though not statistically significantly (99\% CI 0.7 to 5.0 ). 


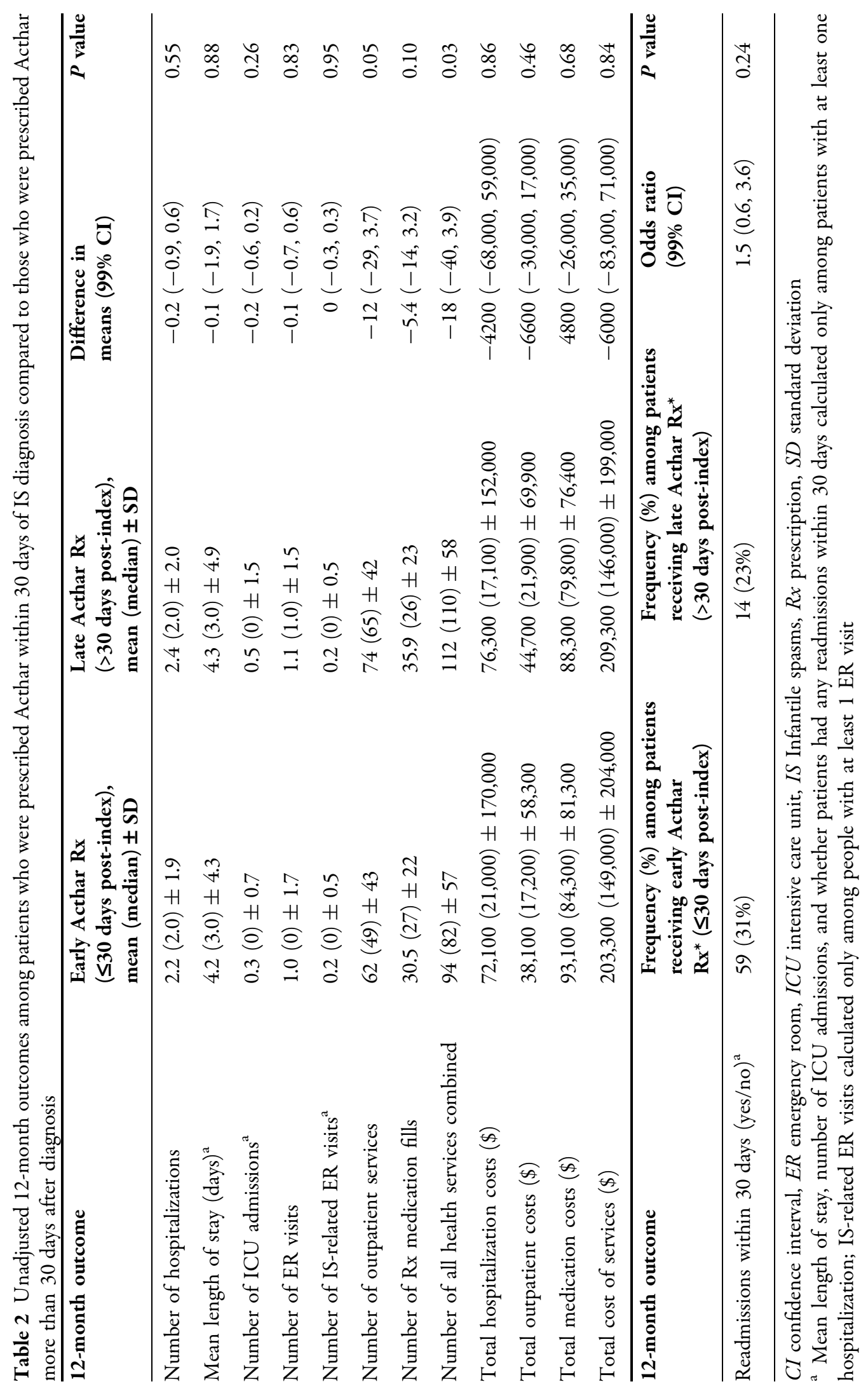




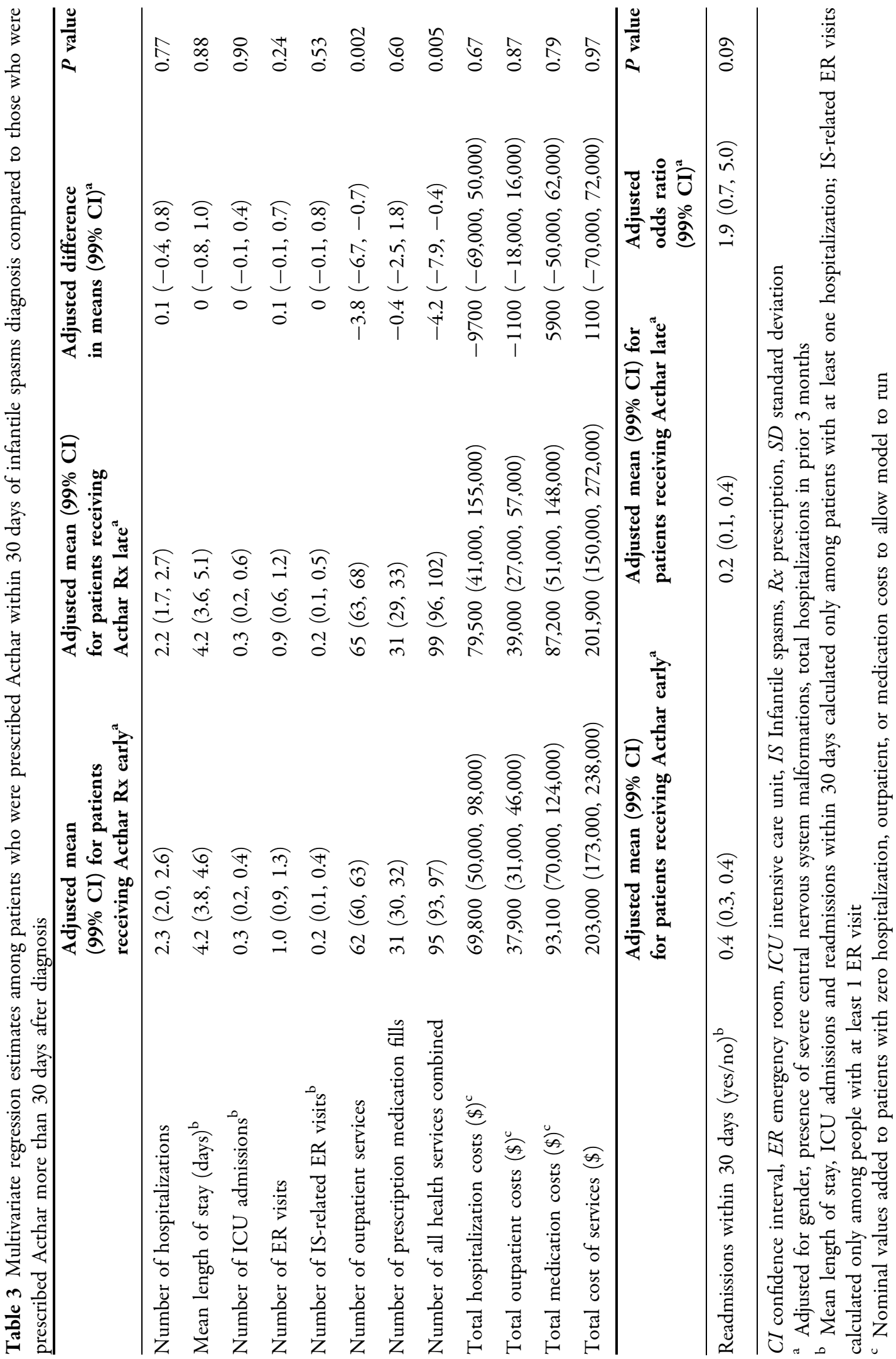




\section{DISCUSSION}

The majority of the patients with IS in our cohort were prescribed Acthar within 30 days of their IS diagnoses. Relative to patients who were prescribed Acthar more than 30 days after diagnosis, the patients prescribed Acthar earlier had fewer outpatient procedures performed. In spite of this reduction in utilization, total costs were similar between the two groups, possibly because the group that received Acthar early had similar numbers of expensive utilizations, such as emergency department visits and inpatient stays. The fact that we observed a two-fold increase in the odds of 30-day readmissions among patients who received Acthar earlier supports this hypothesis.

Although associations between the timing of IS treatment and healthcare utilization and costs have not been well studied, previous research has shown that earlier treatment is associated with improved developmental outcomes [10]. One study showed that earlier treatment for IS significantly improved patients' Vineland Adaptive Behavior Scale (VABS) scores, which measured patients' ability to cope with environmental changes, demonstrate independence, and learn new skills [16]. Another study indicated that neurodevelopmental outcomes are better for infants who have shorter duration of spasms and, therefore, shorter times of epileptic encephalopathy [17]. Our study contributes to evidence that earlier treatment for IS may also be beneficial to achieve less healthcare utilization and lower medication burden.

This study had several limitations. First, exposure to Acthar was predominantly identified through outpatient prescription fills, thus it is possible that some patients were subject to misclassification, because the medication was not actually administered.
However, given that Acthar is a brand name medication that is usually accompanied with a portion of patient cost-sharing, and that we observed patients with multiple prescription fills, we are reassured that the majority of patients with Acthar prescription claims actually received the medication. In addition, because this was an observational study and not a randomized control trial, we cannot be certain that the differences we observed between patients who were prescribed Acthar early versus later could not be explained by confounding factors. We attempted to correct for this by adjusting our models for potentially confounding variables, but unmeasured factors might play a role in the associations that we reported. Because we were interested in outcomes that occurred over the 12 months after the index IS diagnosis, we excluded patients who were not enrolled in their health plans for 1 year after the index event, so our population was stable by definition, and our results are likely not generalizable to more transient populations. We also did not have information on procedures or healthcare resource utilization for which patients paid out-of-pocket rather than filing claims through their insurance companies, and our cost estimates might, therefore, be conservative. Furthermore, the population of patients in the MarketScan databases is not randomly sampled and some populations, such as patients insured by small employers, were not represented in this study population. Therefore, these results may not be generalizable across all patients with IS in the US. Finally, we were unable to account for potential lag times from initial IS symptoms until definitive diagnoses were observed in the claims data. Patients who had been experiencing symptoms for substantial periods of time before their IS diagnosis may have been erroneously placed in the "early" treatment 
category, when in reality, their treatments could have been delayed if measured from the time that their symptoms first occurred. These unmeasured delays likely would have impacted healthcare utilization and costs for these patients.

\section{CONCLUSIONS}

In summary, we determined that earlier prescribing of Acthar to treat IS was associated with fewer outpatient procedures compared to later prescribing of this drug. Future studies should expand upon this descriptive work by focusing on analyzing long-term neurological outcomes both among patients who are prescribed Acthar early versus later, as well as examining outcomes among patients who are prescribed Acthar compared to other IS treatments.

\section{ACKNOWLEDGMENTS}

This study was funded by a grant to the University of Washington from Mallinckrodt Pharmaceuticals (Principal Executive Office: Chesterfield, United Kingdom). The article processing charges and open access fee for this publication were funded by Mallinckrodt Pharmaceuticals. Several of the co-authors on this paper (JN and MP) are employees of the funding agency. All named authors meet the International Committee of Medical Journal Editors (ICMJE) criteria for authorship for this manuscript, take responsibility for the integrity of the work as a whole, and have given final approval to the version to be published. All authors had full access to all of the data in this study and take complete responsibility for the integrity of the data and accuracy of the data analysis.
Disclosures. Patricia B. Schepman is a former employee of Mallinckrodt Pharmaceuticals. Michael Philbin is an employee of Mallinckrodt Pharmaceuticals. John Niewoehner is an employee of Mallinckrodt Pharmaceuticals. Kavitha Damal is a former consultant to Mallinckrodt Pharmaceuticals. Ryan N. Hansen has served on a health economics and outcomes research advisory board for Mallinckrodt Pharmaceuticals and has received research grant funding from Mallinckrodt Pharmaceuticals. Laura S. Gold and Wei-Jhih Wang have no relevant financial disclosures.

Compliance with Ethics Guidelines. All procedures followed were in accordance with the ethical standards of the responsible committee on human experimentation (institutional and national) and with the Helsinki Declaration of 1964, revised in 2013. This study was exempt from review by the University of Washington Institutional Review Board (IRB) through self-determination.

Open Access. This article is distributed under the terms of the Creative Commons Attribution-NonCommercial 4.0 International License (http://creativecommons.org/licenses/ by-nc/4.0/), which permits any noncommercial use, distribution, and reproduction in any medium, provided you give appropriate credit to the original author(s) and the source, provide a link to the Creative Commons license, and indicate if changes were made.

\section{REFERENCES}

1. Trevathan E, Murphy CC, Yeargin-Allsopp M. The descriptive epidemiology of infantile spasms among Atlanta children. Epilepsia. 1999;40(6):748-51. 
2. Pellock JM, Hrachovy R, Shinnar S, et al. Infantile spasms: a US consensus report. Epilepsia. 2010;51(10):2175-89.

3. Sidenvall R, Eeg-Olofsson O. Epidemiology of infantile spasms in Sweden. Epilepsia. 1995;36(6):572-4.

4. Luthvigsson P, Olafsson E, Sigurthardottir S, Hauser WA. Epidemiologic features of infantile spasms in Iceland. Epilepsia. 1994;35(4):802-5.

5. Wheless JW, Gibson PA, Rosbeck KL, et al. Infantile spasms (West syndrome): update and resources for pediatricians and providers to share with parents. BMC Pediatr. 2012;12:108.

6. Matsumoto A, Watanabe $\mathrm{K}$, Negoro $\mathrm{T}$, et al. Long-term prognosis after infantile spasms: a statistical study of prognostic factors in 200 cases. Dev Med Child Neurol. 1981;23(1):51-65.

7. Saemundsen E, Ludvigsson P, Rafnsson V. Risk of autism spectrum disorders after infantile spasms: a population-based study nested in a cohort with seizures in the first year of life. Epilepsia. 2008;49(11):1865-70.

8. Hrachovy RA, Frost JD Jr. Infantile epileptic encephalopathy with hypsarrhythmia (infantile spasms/West syndrome). J Clin Neurophysiol Off Publ Am Electroencephalogr Soc. 2003;20(6):408-25.

9. Widjaja E, Go C, McCoy B, Snead OC. Neurodevelopmental outcome of infantile spasms: a systematic review and meta-analysis. Epilepsy Res. 2015;109:155-62.

10. Lombroso CT. A prospective study of infantile spasms: clinical and therapeutic correlations. Epilepsia. 1983;24(2):135-58.
11. Joshi C, Berg AT, Wirrell E. Do patients require inpatient admission to receive adrenocorticotropic hormone (ACTH)? A survey of US-based prescribers. J Child Neurol. 2015;31:164-9.

12. US Food and Drug Administration. Sabril Approved by FDA to Treat Spasms in Infants and Epileptic Seizures: U.S. Food and Drug Administration; 2009. http://www.fda.gov/NewsEvents/Newsroom/Press Announcements/ucm179855.htm. Accessed 17 December 2015. (Updated 21 August 2009).

13. US Food and Drug Administration. Drug approval package: H.P. Acthar gel (repository corticotropin) injection 2010. http://www.accessdata.fda.gov/ drugsatfda_docs/nda/2010/022432_hp_acthar_gel_ toc.cfm. Accessed 17 December 2015.

14. Mallinckrodt Pharmaceuticals I. H.P. Acthar gel package insert 2015. http://www.acthar.com/pdf/ Acthar-PI.pdf. Accessed 15 Sept 2015.

15. Krueger DA, Northrup H. International tuberous sclerosis complex consensus G. Tuberous sclerosis complex surveillance and management: recommendations of the 2012 international tuberous sclerosis complex consensus conference. Pediatr Neurol. 2013;49(4):255-65.

16. O'Callaghan FJ, Lux AL, Darke K, et al. The effect of lead time to treatment and of age of onset on developmental outcome at 4 years in infantile spasms: evidence from the United Kingdom infantile spasms study. Epilepsia. 2011;52(7):1359-64.

17. Rener-Primec Z, Lozar-Krivec J, Krivec U, Neubauer D. Head growth in infants with infantile spasms may be temporarily reduced. Pediatr Neurol. 2006;35(3):197-203. 